\title{
STUDI PERENCANAAN PENINGKATAN JARINGAN IRIGASI PADA DAERAH IRIGASI KODI DI KABUPATEN SUMBA BARAT DAYA
}

\author{
Melchior Kase ${ }^{1}$, Onisius Loden ${ }^{2}$, Matelda Ch. Mauta ${ }^{3}$, Theresia A. Bria ${ }^{4}$ \\ ${ }^{1}$ Alumni Teknik Sipil Prodi Teknik Perancangan Irigasi dan Penanganan Pantai, Politeknik Negeri Kupang \\ 234Jurusan Teknik Sipil,Politeknik Negeri Kupang \\ Jl. Adisucipto Penfui, Kupang, Indonesia \\ Email : chyor109@gmail.com¹, oniloden 2008@yahoo.co.id², mateldamauta@yahoo.co.id³. \\ thessa_Bria@yahoo.co.id ${ }^{4}$
}

\begin{abstract}
Abstrak
Irigasi merupakan kegiatan-kegiatan yang berhubungan dengan usaha mendapatkan air untuk mengairi sawah, ladang, perkebunan, yang sebagai intinya adalah untuk keperluan pertanian dalam usaha tani. Daerah Irigasi Kodi yang secara administratif berada di Desa Watu Wona, Kecamatan Kodi, Kabupaten Sumba Barat Daya, Propinsi Nusa Tenggara Timur. Sumber air Daerah Irigasi ini berasal dari sungai Bondo Kodi yang memiliki areal potensial seluas $3.000 \mathrm{Ha}$ dan 729,09 ha untuk saluran sekunderKawango Hari. Musim tanam yang berlangsung adalah 3 musim tanam yakni padi-palawija-palawija.Tujuan dari penelitian ini untuk merencanakan jaringan irigasi agar kebutuhan air pada daerah irigasi Kodi Kabupaten Sumba Barat Daya dapat terpenuhi. Data atau informasi yang digunakan adalah data sekunder yang diperoleh dari Balai Wilayah Sungai Nusa Tenggara II yaitu data topografi, data curah hujan dan data klimatologi 10 tahun terakhir dari tahun 2008 sampai dengan tahun 2017 dan data primer diperoleh dari survey langsung di lapangan yaitu pengukuran situasi saluran irigasi, pengukuan debit sesaat, pengukuran dimensi saluran yang ada, pengkuran panjang saluran yang telah ada Metode pengolahan data menggunakan perhitungan secara manual sesuai dengan metode Penman Modifikasi untuk menghitung evapotranspirasi, metode Dr. F. J. Mock untuk menghitung debit andalan, menghitung kebutuhan air irigasi (NFR) dan rumus strickler untuk debit saluran. Setelah dilakukan perhitungan maka didapat nilai evapotranspirasi Potensial Metode Penman Modifikasi sebesar 3,115 mm/hari, kebutuhan air irigasi(NFR) sebesar 1,39 $\mathrm{ltr} / \mathrm{dtk} / \mathrm{ha}$, debit rencana saluran sebesar $1,5625 \mathrm{~m}^{3} / \mathrm{dtk}$ dan dimensi saluran untuk saluran sekunder ruas Kawango Hari adalah Lebar saluran $(B)=2,06$ meter, Tinggi muka air $(\mathrm{h})=2,06$ meter, tinggi jagaan $(w)=0,25$ meter.
\end{abstract}

Kata Kunci : Irigasi, Debit,Dimensi, Saluran

\section{PENDAHULUAN}

Dalam beberapa tahun terakhir, modernisasi sistem irigasi, dari sistem gravitasi ke sistem bertekanan, telah menyebabkan peningkatan produktivitas air dan lahan tetapi juga peningkatan konsumsi energi (Fernández García et al., 2014a; Tarjuelo et al., 2015). Dalam masyarakat irigasi, peningkatan biaya energi, bersama dengan biaya investasi yang terkait dengan modernisasi, dapat membahayakan kelangsungan ekonomi beberapa pertanian modern.

Kurangnya pengetahuan tentang hubungan antara air dan penggunaan energi dapat menyebabkan peningkatan biaya energi. Fakta ini sangat relevan dengan jaringan irigasi sesuai permintaan, di mana penggunaan air yang tidak efisien serta peningkatan yang signifikan dalam konsumsi energi dapat terjadi, bahkan ketika petani tidak menjadwalkan irigasi dengan memadai. Dalam jenis jaringan irigasi ini, biasanya, petani mengairi kapan saja mereka inginkan, dan ini ditandai dengan fleksibilitas manajemen irigasi (Lamaddalena dan Sagardoy, 2000). Manajemen ini mengalami variabilitas rezim aliran yang tinggi karena tergantung pada jumlah hidran yang dibuka secara terpisah, yang dapat berkontribusi pada efisiensi energi yang rendah di beberapa jaringan irigasi ini karena stasiun pompa tidak bekerja dalam kondisi yang dirancang (Lamaddalena dan Pereira , 2007; Rodríguez Díaz et al., 2009) Modernisasi sistem irigasi di daerah 
semi-kering telah meningkatkan efisiensi penggunaan air, tetapi pada saat yang sama telah terjadi peningkatan besar dalam konsumsi energi (Jackson et al., 2010; Corominas, 2010) dan bersamaan dengan harga tanaman yang rendah ini telah mengurangi profitabilitas pertanian irigasi di daerah-daerah ini.

Semua tindakan ini dikembangkan untuk jaringan irigasi sesuai permintaan. Namun, dari sudut pandang operasional, ketika operasi pengguna dibatasi pada periode waktu tertentu, kepala yang diperlukan dapat dikurangi, serta konsumsi energi. Untuk menilai bagaimana pendekatan ini akan meningkatkan efisiensi energi, Rodríguez et al. (2009) mempelajari potensi penghematan dalam studi kasus dengan mensimulasikan perubahan sistem operasi dari on-demand menjadi operasi berdasarkan sektor. Jaringan irigasi dibagi menjadi dua sektor menurut kriteria elevasi yang homogen. Setiap hidran dari kedua sektor dapat bekerja secara bebas pada periode yang ditentukan (12 jam). Disimpulkan bahwa penghematan energi bisa setinggi $27 \%$

Tujuan pemerintah untuk mencapai masyarakat Indonesia yang adil, makmur dan sejahtera merupakan cita-cita luhur Bangsa Indonesia yang tertuang dalam Alinea IV Pembukaan Undang-undang Dasar 1945. Hal ini perlu didukung oleh beberapa faktor diantaranya sumber daya alam dan sumber daya manusia.. Dalam rangka meningkatkan kesejahteraan petani diperlukan penyediaan sarana dan prasarana irigasi untuk mengairi lahan pertanian. Untuk memaksimalkan hal tersebut maka diperlukan suatu perencanaan teknis dalam rangka pemeliharaan jaringan irigasi agar dapat berfungsi secara optimal, sehingga kebutuhan air irigasi dapat terpenuhi.

\section{METODOLOGI PENELITIAN}

\section{Sumber Data}

Sumber data dalam yaitu data primer dan data sekunder.

1). Data primer adalah data yang diperoleh dari penelitian langsung di lokasi penelitian. Data primer berupa :

a. Pengukuran situasi saluran irigasi

b. Pengukuran debit sesaat

c. Pengukuran dimensi saluran yang ada

d. Wawancara (interview)

e. Pengukuran panjang saluran yang telah ada

2). Data sekunder adalah data yang diperoleh dari instanasi terkait yag berhubungan dengan penelitian. Datadata tersebut adalah :

a. Data curah hujan

Data curah hujan di peroleh dari Balai Wilayah Sungai Nusa

Tenggara II. Data ini digunakan untuk menghitung menghitung debit rencana.

b. Data klimatologi

Data klimatologi diperoleh dari Balai Wilayah Sungai Nusa Tenggara II. Data ini digunakan untuk menghitung nilai evapotranspirasi.

\section{Bagan Alir Penulisan}

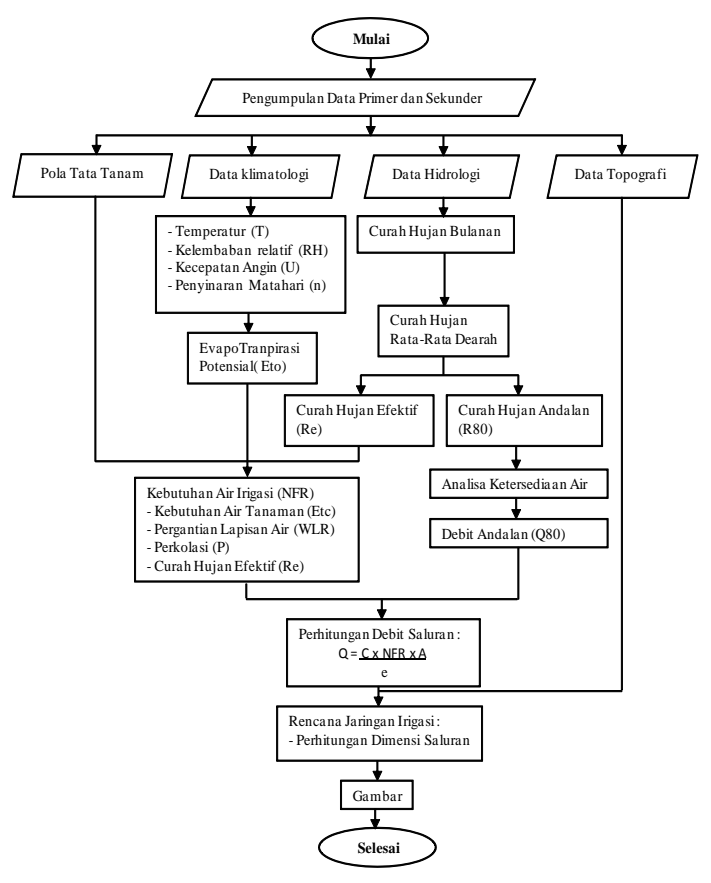

Gambar 1. Bagan Alir Penulisan

\section{PEMBAHASAN}

1. Perhitungan Evapotranspirasi

Besarnya evapotranspirasi sangat tergantung dari beberapa faktor antara lain yang diambil dari data klimatologi seperti :
a. Kecepatan angin ( $u$ )
b. Kelembaban relatif $(R H)$
c. Temperatur udara $(T)$

Penyinaran matahari (n) Contoh perhitungan Evapotranspirasi untuk bulan November :

Data Klimatologi Stasiun Waingapu

Elevasi stasiun klimatologi $=10 \mathrm{~m} \mathrm{dpl}$

Elevasi daerah irigasi $=145 \mathrm{~m} \mathrm{dpl}$ 


$$
\begin{aligned}
& \Delta \mathrm{H} \quad=145-10 \\
& \begin{array}{ll} 
& =135 \mathrm{~m} \\
& =0,25 \text { (konstanta) }
\end{array} \\
& b \quad=0,50 \text { (konstanta) } \\
& \text { Koordinat } \quad=09^{\circ} 40^{\prime} 26^{\prime \prime} \text { LS } \\
& =120^{\circ} 18^{\prime} \text { '52" BT }
\end{aligned}
$$

1. Temperatur $(\mathrm{T})$

Data temperatur $(T)$ diperoleh dari data klimatologi stasiun Waingapu dalam derajat celcius $\left({ }^{\circ} \mathrm{C}\right)$. Diambil nilai ratarata temperatur bulan November dari tahun 2008 - tahun 2017.

$$
\begin{aligned}
& =\frac{\text { Jumlah data temperatur }}{\text { Jumlah data }} \\
& =\frac{285,8^{0} \mathrm{C}}{10} \\
& =28,58^{\circ} \mathrm{C}
\end{aligned}
$$

2. Kecepatan angin $(U)$

Data kecepatan angin (U) diperoleh dari data klimatologi stasiun Waingapu dalam $\mathrm{m} / \mathrm{dt}$. Diambil nila irata-rata kecepatan angin $(\mathrm{U})$ bulan November dari tahun 2008 - tahun 2017.

$$
\begin{aligned}
(U)= & \frac{\text { Jumlah data Kec. Angin }}{\text { Jumlah data }} \\
= & \frac{48 \text { Knots }}{10}=4,80 \mathrm{Knots} \\
& (1 \mathrm{Knots}=1,852 \mathrm{~km} / \mathrm{jam}) \\
= & 4,80 \times 1,852 \mathrm{~km} / \mathrm{jam} \\
= & 8,881 \mathrm{~km} / \mathrm{jam} \times 24 \mathrm{jam} \\
= & 213,14 \mathrm{~km} / \mathrm{hari}
\end{aligned}
$$

3. Kelembaban udara relatif $(\mathrm{Rh})$

Data kelembaban udara relatif (Rh) diperoleh dari data klimatologi stasiun Waingapu dalam persen (\%). Diambil nilai rata-rata kelembaban relatif $(R h)$ bulan November (dari tahun 2008 tahun 2017).

$$
\begin{aligned}
(R h)= & \frac{\text { Jumlah data Kelembaban Relatif }}{\text { Jumlah data }} \\
= & \frac{746 \%}{10} \\
= & 74,6 \%
\end{aligned}
$$

4. Penyinaran matahari $(\mathrm{n})$

Data penyinaran matahari (n) diperoleh dari data klimatologi stasiun Waingapu dalam persen (\%). Diambil nilai rata-rata kelembaban relatif $(\mathrm{Rh})$ bulan Januari (dari tahun 2008 - tahun 2017).

$$
\text { (n) } \begin{aligned}
\frac{\text { Jumlah penyinaran matahari }}{\text { Jumlah data }} & = \\
= & \frac{811 \%}{10} \\
= & 81,1 \%
\end{aligned}
$$

I. Koreksi data

Data yang dikoreksi merupakan temperatur $(T)$ dan penyinaran matahari (n) dengan :

$$
\begin{aligned}
\mathrm{T} & =28,53^{\circ} \mathrm{C} \\
\mathrm{n} & =81,10 \% \\
\Delta \mathrm{H} & =135 \mathrm{~m}
\end{aligned}
$$

5. $T=T+(0,006 \times \Delta \mathrm{H})$

$$
\begin{aligned}
& =28,58+(0,006 \times 135) \\
& =27,77 \stackrel{\circ}{ } \mathrm{C} \\
& =n+(0,010 \times \Delta \mathrm{H}) \\
& =81,10+(0,010 \times 135) \\
& =79,75 \%
\end{aligned}
$$$$
\text { 6. } n=n+(0,010 \times \Delta \mathrm{H})
$$

II. Analisa data

7. TekananUap Air (ea)

Tekananuap air (ea) dalam mbar. Untuk mendapatkan nilai tekanan uap air (ea) diinterpolasi dari tabel 2.9 berdasarkan nilai temperatur $(T)$ rerata bulan November.

Diketahui :

$T f\left(X_{i}\right) \quad=28,58 \stackrel{\circ}{\circ} \mathrm{C}$

(nilai TbulanNovember)

Tabel 4.1 Data nilaitekananuap air (ea)

\begin{tabular}{|c|c|}
\hline Temperatur ${ }^{0} \mathrm{C}$ & ea (mbar) \\
\hline $28^{\circ} \mathrm{C}\left(Z_{1}\right)$ & $37,80\left(X_{1}\right)$ \\
\hline $28,58^{\circ} \mathrm{C}\left(X_{i}\right)$ & $?$ \\
\hline $29^{\circ} \mathrm{C}\left(Z_{2}\right)$ & $40,10\left(X_{2}\right)$ \\
\hline
\end{tabular}

Mencari nilai $f(X i)$ dengan cara interpolasi linear :

$$
\begin{aligned}
& f(X i)=\frac{\left(Z_{2}-Z i\right)\left(X_{1}\right)-\left(Z_{1}-Z i\right)\left(X_{2}\right)}{Z_{2}-Z_{1}} \\
& f(28,58)=39,134 \text { mbar. }
\end{aligned}
$$

8. Tekanan Jenuh Uap Air (ed) 


\begin{tabular}{|c|c|c|c|}
\hline & $X i$ & $f(X i)$ & $(X i-X o)$ \\
\hline & 28 & 0,767 & $-0,58$ \\
\hline$X_{0}$ & 28,58 & & \\
\hline & 30 & 0,780 & 1,42 \\
\hline
\end{tabular}

air (ed) dihitung dengan rumus berikut :

ed $=$ ea $. R h / 100$

dengan :

ed =tekananuap air jenuh (mbar)

ea $=39,134 \mathrm{mbar}$ (tekananuap

air)

$\mathrm{Rh} \quad=74,60 \%$ (Kelembabanrelatif)

Maka,

ed $\quad=39,134 \cdot 74,60 / 100$

$=29,194$ mbar.

9. Perbedaan tekanan uap air jenuh (ed) dengan tekanan uap air (ea)

ea - ed $=39,134$ mbar $-29,194$ mbar $=9,940$ mbar.

10. Fungsikecepatanangin $f(u)$

Fungsikecepatanangindihitungdenganru musberikut :

$f(u) \quad=0,27(1+0,864 U)$

Dimana :

$f(u) \quad=213,14 \mathrm{~m} / \mathrm{dt}$

(kecepatananginbulanNovember)

Maka,

$f(u) \quad=0,27\left(1+0,864^{\star} 213,14\right)$

$=0,500 \mathrm{~m} / \mathrm{dt}$

11. $(1-W)$ bulan November $=$ Diinterpolasi dari Tabel 2.3

\begin{tabular}{|c|c|}
\hline$(1-w)$ pada Ketinggian & 145 \\
\hline Temperatur ${ }^{\circ} \mathrm{C}$ & \\
\hline 28 & 0,233 \\
\hline 28,58 & $f(X i)$ \\
\hline 30 & 0,220 \\
\hline
\end{tabular}

Mencari nilai $f(X i)$ harga Xo dengan cara interpolasi linear :

$f(X i) \quad=\frac{(1,42)(0,2 a 3)-(-0,58)(0,220)}{10}$

$f(28,58)=0,229$

12. $(W)$ bulan November $=$ Diinterpolasi dari Tabel 2.10

W pada El. (m) 145

\begin{tabular}{|c|c|}
\hline Temperatur ${ }^{\circ} \mathrm{C}$ & \\
\hline 28 & 0,767 \\
\hline 28,58 & $f(X i)$ \\
\hline 30 & 0,780 \\
\hline
\end{tabular}

Interpolasi Linear :

Mencari nilai $f(X i)$ harga Xo dengan cara interpolasi linear :

$f(X i)$

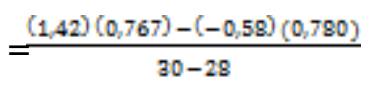

$f(28,58)=0,771$

13. Ra bulan November $=$ Diinterpolasi dari Tabel 2.5

Koordinat Stasiun Klimatologi

09॰ 40' 26" LS

$$
\begin{array}{ll}
\text { LS } & =09 \circ+40 / 60+26 / 3600 \\
& =09 \circ+0,67+0,0072 \\
\text { LS } & =9,67 \circ
\end{array}
$$

\begin{tabular}{|c|c|}
\hline Lintang Selatan & November \\
\hline 8 & 16,0 \\
\hline 9,67 & $f(X i)$ \\
\hline 10 & 16,2 \\
\hline
\end{tabular}

Interpolasi Linear :

\begin{tabular}{|c|c|c|c|}
\hline & $X i$ & $f(X i)$ & $\left(X i-X_{0}\right)$ \\
\hline $\begin{array}{c}\text { Xo } \\
\text { M }\end{array}$ & 9,67 & 16,0 & $-1,67$ \\
\hline $\begin{array}{c}\text { e } \\
\text { n }\end{array}$ & 10 & 16,2 & 0,33 \\
\hline
\end{tabular}

cari nilai $f(X i)$ harga Xo dengan cara interpolasi linear :

$f(X i)$

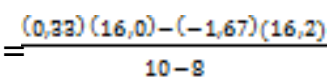

$f(9,67)=16,167$

14. (n) bulan November

$=(\mathrm{n} / 100) / 12,1$

$=79,75 / 100 / 12,1$

$=0,066$

15. $(N)=$ Diinterpolasi dari Tabel 2.4 Koordinat Stasiun Klimatologi 09。 40' 26" LS

$$
\begin{array}{ll}
\text { LS } & =09 \circ+40 / 60+26 / 3600 \\
& =09^{\circ}+0,67+0,0072 \\
\text { LS } & =9,67^{\circ}
\end{array}
$$

\begin{tabular}{|c|c|}
\hline Lintang Selatan & November \\
\hline 5 & 12,3 \\
\hline
\end{tabular}




\begin{tabular}{|c|c|}
\hline 9,67 & $f(X i)$ \\
\hline 10 & 12,6 \\
\hline
\end{tabular}

Interpolasi Linear :

\begin{tabular}{|l|c|c|c|}
\hline & $X i$ & $f(X i)$ & $(X i-X o)$ \\
\hline & 5 & 12,3 & $-4,67$ \\
\hline $\begin{array}{l}\text { Xo } \\
M \\
e\end{array}$ & 9,67 & & \\
\hline
\end{tabular}

cari nilai $f(X i)$ harga Xo dengan cara interpolasi linear :

$f(X i) \quad=\frac{(0, a a)(12, a)-(-4,67)(12,6)}{10-5}$

$f(9,67)=12,580$

16. $n / N$ bulan November

$=0,066 / 12,580$

$=0,005$

17. Rs bulan November

$=(a+b \cdot n / N) R a$

$=(0,25+(0,50 \times 0,005)) \times 16,167$

$=4,084 \mathrm{~mm} /$ hari

18. Rns bulan November

$=(1-a) R s$

$=(1-0,25) \times 4,084$

$=3,063 \mathrm{~mm} /$ hari

19. $f(T)$ bulan November

= Diinterpolasi dari Tabel 2.6

\begin{tabular}{|l|c|c|c|}
\hline Temp.(oC) & 28 & 28,58 & 30 \\
\hline$f(T)$ & 16,3 & $f(X i)$ & 16.7 \\
\hline
\end{tabular}

Interpolasi Linear :

\begin{tabular}{|c|c|c|c|}
\hline & $X i$ & $f(X i)$ & $(X i-X o)$ \\
\hline & 28 & 16,3 & $-0,58$ \\
\hline$X o$ & 28,58 & & \\
\hline & 30 & 16,7 & 1,42 \\
\hline
\end{tabular}

Mencari nilai $f(X i)$ harga Xo dengan cara interpolasi linear :

$f(X i) \quad=\frac{[1,42)(16, \mathrm{a})-[-0,58)(16,7)}{\mathrm{a} 0-28}$

$f(28,58)=16,42$
20. $f(e d)$ bulan November

$=$ Diinterpolasi dari Tabel 2.7

\begin{tabular}{|l|l|l|l|}
\hline ed (mmbar) & 28 & 29,194 & 30 \\
\hline $\begin{array}{l}f(e d)=0.34 \\
-0,044 \\
(e d)^{0.5}\end{array}$ & 0,11 & $f(X i)$ & 0,10 \\
\hline
\end{tabular}

Interpolasi Linear :

\begin{tabular}{|l|c|c|c|}
\hline & $X i$ & $f(X i)$ & $(X i-X o)$ \\
\hline & 28 & 0,11 & $-1,19$ \\
\hline $\begin{array}{l}\text { Xo } \\
M\end{array}$ & 29,194 & & \\
\hline $\begin{array}{l}n \\
n\end{array}$ & 30 & 0,10 & 0,81 \\
\hline
\end{tabular}

cari nilai $f(X i)$ harga Xo dengan cara

\begin{tabular}{|c|c|c|c|}
\hline & $X i$ & $f(X i)$ & $\left(X i-X_{0}\right)$ \\
\hline & 0,00 & 0,1 & $-0,005$ \\
\hline$X_{0}$ & 0,005 & & \\
\hline & 0,05 & 0,2 & 0,045 \\
\hline
\end{tabular}

interpolasi linear :

$f(X i) \quad=\frac{[0,91)(0,11]-[-1,19)(0,10)}{30-28}$

$f(29,194)=0,104$

21. $f(n / N)$ bulan November

Diinterpolasi dari Tabel 2.8

\begin{tabular}{|l|l|l|l|}
\hline$n / N$ & 0.00 & 0.005 & 0.05 \\
\hline$f(n / N)$ & 0.10 & $f(X i)$ & 0.2 \\
\hline
\end{tabular}

Interpolasi Linear :

Mencari nilai $f(X i)$ harga Xo dengan cara interpolasi linear :

$f(X i) \quad=\frac{(0,045)(0,1)-(-0,005)(0,2)}{0,05-0,00}$

$f(0,006)=0,105$

22. Rn1 bulan November

$=f(T) \cdot f(e d) \cdot f(n / N)$

$=16,42 \times 0,104 \times 0,105$

$=0,180 \mathrm{~mm} /$ hari

23. $R n$ bulan November

$=R n s-R n 1$

$=3,063-0,180$

$=2,883 \mathrm{~mm} /$ hari

24. Kecepatan angin rata- rata (Ud) bulan November 
$\mathrm{Ud}=(\mathrm{u} \times 1000) /\left(60^{2} \times 24\right)$

$=(213,14 \times 1000) /\left(60^{2} \times 24\right)$

$=2,467 \mathrm{~mm} / \mathrm{dtk}$

25. Faktor perkiraan kondisi musim (C) bulan November= Diinterpolasi dari Tabel 2.11

\begin{tabular}{|c|c|}
\hline \multicolumn{2}{|c|}{$R H$ max $=90 \%$} \\
\hline \multicolumn{2}{|c|}{ Uday/Unight $=2.0$} \\
\hline Rs $\mathrm{mm} /$ hari & 4.084 \\
\hline Uday $\mathrm{m} / \mathrm{dt}$ & 1,02 \\
\hline 0 & $Y$ \\
\hline 2,467 & 0,89 \\
\hline 3 & \\
\hline
\end{tabular}

Mencari nilai $f(X i)$ harga Xo dengan cara interpolasi linear:

$f(X i) \quad=\frac{(0,5 a a)(1,02)-(-2,467)(0,89)}{a-0}$

$f(2,467)=0,927$

26. Evapotranspirasi potensial (ETo)bulan November

Eto $=$

$$
\begin{aligned}
\text { c. } & {\left[W \cdot R_{n}+(1-W) \cdot f \cdot(u) \cdot\left(e_{a}-e_{d}\right)\right] } \\
= & 0,927 \cdot[0,771 \cdot 2,883+(0,229) 0,500 \\
& (9,940)] \\
= & 3,115 \mathrm{~mm} / \text { hari }
\end{aligned}
$$

Tabel 1. Perhitungan Evapotranspirasi Potensial

\begin{tabular}{|c|c|}
\hline Bulan & $\begin{array}{c}\text { Eto } \\
\text { (mm/hari) }\end{array}$ \\
\hline Jan & 2,813 \\
\hline Feb & 2,415 \\
\hline Mar & 2,584 \\
\hline Apr & 2,580 \\
\hline Mei & 2,499 \\
\hline Juni & 2,446 \\
\hline Juli & 2,608 \\
\hline
\end{tabular}

Nama Penulis ${ }^{1 *}$, Nama Penulis ${ }^{2}$, dan Nama Penulis ${ }^{3}$

\begin{tabular}{|c|c|}
\hline Agust & 2,754 \\
\hline Sep & 2,966 \\
\hline Okt & 3,162 \\
\hline Nop & $\mathbf{3 , 1 1 5}$ \\
\hline Des & 2,850 \\
\hline
\end{tabular}

2. Perhitungan Ketersediaan Air Irigasi Contoh perhitungan ketersediaan air irigasi untuk tahun 2017 di bulan November I :

$$
\text { Luas DAS }=68,7 \mathrm{~km}^{2}
$$

I. Data Hujan $(P)=0+0+0+0+0+2+0+0+0+0+0+$ $0+0+0+0$
1. Curah hujan $1 / 2$ bulanan
$=2,00 \mathrm{~mm} /$ hari

2. Hari hujan $1 / 2$ bulanan

(h) $=15$ hari

II. Evapotranspirasi terbatas (Et)

3. Evapotranspirasi potensial $1 / 2$ bulanan

$$
\begin{aligned}
\text { (Eto) } & =\text { Eto } \times 15 \text { hari } \\
& =3,115 \times 15 \\
& =46,72 \mathrm{~mm} / \text { hari }
\end{aligned}
$$

4. Permukaan lahan terbuka $(\mathrm{m})=$ 40\% (diperuntukan untuk lahan pertanian yang diolah dengan asumsi $m=30 \%-50 \%$ )

5. Perbedaan antara (Eto) dan evapotranspirasi terbatas (Et)

$\mathrm{E}=(\mathrm{ETo}){ }^{*}(\mathrm{~m} / 20) *(18-\mathrm{h})$

$=46,72 *\left(\frac{4036}{20}\right) *(18-15)$

$=2,80 \mathrm{~mm} /$ hari

6. $\mathrm{Et}=(\mathrm{Eto})-\mathrm{E}$

$$
\begin{aligned}
& =46,72-2,80 \\
& =43,92 \mathrm{~mm} / \text { hari }
\end{aligned}
$$

III. Keseimbangan air

7. Air hujan yang mencapai permukaan tanah

$\Delta \mathrm{s}=\mathrm{P}-\mathrm{Et}$

$=2-43,92$

$=-41,92 \mathrm{~mm} /$ hari (defisit)

8. Kandungan air tanah (Is) Is $=-41,92 \mathrm{~mm} /$ hari.

9. Kapasitas kelembapan tanah Nilai SMC diambil $=200 \mathrm{~mm}$ 
10. Kelebihan air

$$
\begin{aligned}
\text { WS } & =\Delta s-\text { Is } \\
& =(-41,92)-(-41,92) \\
& =0,00 \mathrm{~mm} / \text { hari }
\end{aligned}
$$

IV. Aliran dan Penyimpanan Air Tanah

Koefisien Infiltrasi (i) diambil $=0,8$

Faktor resesi aliran air tanah $(k)=0,9$

11. Infiltrasi

$$
\begin{aligned}
(I)=W s^{*} i & \\
& =0,00 * 0,8 \\
& =0,00 \mathrm{~mm} / \text { hari }
\end{aligned}
$$

$\begin{array}{cl}\text { Feb II } & 3,020 \\ \text { Mar I } & 2,890 \\ \text { Mar II } & 2,020 \\ \text { Apr I } & 3,300 \\ \text { Apr II } & 2,140 \\ \text { Mei I } & 1,930 \\ \text { Mei II } & 1,630 \\ \text { Juni I } & 1,560 \\ \text { Juni II } & 1,410 \\ \text { Juli I } & 1,260 \\ \text { Juli II } & 1,070\end{array}$

13. Perubahan volume air

$$
\begin{aligned}
(\mathrm{DVn}) & =\mathrm{Vn}-\mathrm{V}_{(\mathrm{n}-1)} \\
& =92,45-102,73 \\
& =(-10,27 \mathrm{~mm} / \text { hari })
\end{aligned}
$$

Agust I $\quad 1,020$

Agust II $\quad 0,860$

14. Aliran dasar

$$
\text { (BF) } \quad \begin{aligned}
= & \mathrm{Dn}-\mathrm{I} \\
& =(-10,27)-0,00 \\
& =10,27 \mathrm{~mm} / \text { hari }
\end{aligned}
$$

Sept I $\quad 0,830$

Sept II $\quad 0,750$

15. Aliran langsung

$$
\begin{aligned}
(\mathrm{DR}) & =\mathrm{WS}-\mathrm{I} \\
& =0,00-0,00 \\
& =0,00 \mathrm{~mm} / \text { hari }
\end{aligned}
$$

16. Aliran

$$
\begin{aligned}
(\mathrm{R}) & =\mathrm{BF}+\mathrm{DR} \\
& =10,27+0,00 \\
& =10,27 \mathrm{~mm} / \text { hari }
\end{aligned}
$$

V. Debit Aliran Sungai

17. Debit aliran sungai

$$
\begin{aligned}
& =\left(A^{*} R^{*} 1000\right) /\left(86400^{*} \text { Jumlah Hari }\right) \\
& =\left(68,7^{*} 10,27^{*} 1000\right) /\left(86400^{*} 15\right) \\
& =\mathbf{0}, \mathbf{5 4 5} \mathbf{~ m}^{3} / \mathbf{d t k}
\end{aligned}
$$

Tabel 2. Perhitungan Debit Andalan Tahun 2017 bulan Nop. I

\begin{tabular}{cc}
\hline Bulan & $\begin{array}{c}\text { Debit Aliran Sungai } \\
\left(\mathbf{m}^{3} / \mathbf{d t k}\right)\end{array}$ \\
\hline Jan I & 1,000 \\
Jan II & 3,670 \\
Feb I & 2,820
\end{tabular}


perencanaan irigasi $\mathrm{KP}$

ditetapkan sebesar $2 \mathrm{~mm} / \mathrm{hari}$

4. Penggunaan konsumtif atau Etc $=$ k.Et0

Untuk LP maka nilai Etc diambil dari perhitungan penyiapan lahan buulan April sebesar 9,97 mm/hri

5. Penggantian lapisan air pada bulan April I nilai WLR sebesar 0 karena belum ada pemupukan jadi tidak perlu mengganti lapisan air

6. Total kebutuhan air

$=$ Perkolasi + Penggunaan Konsumtif + WLR rata-rata

$=2+9,97+0$

$=11,97 \mathrm{~mm} / \mathrm{hr}$

7. Hujan efektif untuk padi pada bulan nopember $0,00 \mathrm{~mm} / \mathrm{hr}$

8. Kebutuhan air bersih

$=$ total kebutuhan air-hujan efektif

$=11,97-0,00$

$=11,97 \mathrm{~mm} / \mathrm{hr}$

9. Nilai 0,116 diperoleh dari :

$1 \mathrm{~mm} /$ hari $=$ It/dtk/ha

$1 \mathrm{~mm} /$ hari $=$ $\frac{0,01 \times 1,000.000}{60 \times 60 \times 24}$

$=\frac{10.000}{86.400}$

$=0,116 \mathrm{It} / \mathrm{dtk} / \mathrm{ha}$

10. Kebutuhan air di sawah (NFR)

$N F R=$ Kebutuhan air bersih $\times 0,116$ $=11,97 \mathrm{~mm} /$ hri $\times 0,116$

$=1,39 \mathrm{lt} / \mathrm{dtk} / \mathrm{ha}$

11. Efisiensi irigasi (e)

$$
\begin{array}{ll}
= & 0,9 \cdot 0,9 \cdot 0,8 \\
= & 0,65
\end{array}
$$

12. Kebutuhan air di intake untuk bulan November I

$$
\begin{aligned}
D R & =N F R / e \\
& =1,39 / 0,65 \\
& =2,141 \mathrm{t} / \mathrm{dt} / \mathrm{ha}
\end{aligned}
$$

\begin{tabular}{|c|c|}
\hline Bulan & $\begin{array}{c}\text { Kebutuhan Air } \\
\text { Irigasi Di Sawah } \\
\text { (It/dtk/ha) }\end{array}$ \\
\hline Jan I & 0,95 \\
\hline Jan II & 0,42 \\
\hline Feb I & 0,35 \\
\hline Feb II & 0,50 \\
\hline Mar I & 0,39 \\
\hline Mar II & 0,43 \\
\hline Apr I & 0,23 \\
\hline Apr II & 1,39 \\
\hline Mei I & 1,31 \\
\hline Mei II & 1,31 \\
\hline Juni I & 0,58 \\
\hline Juni II & 0,57 \\
\hline Juli I & 0,70 \\
\hline Juli II & 0,46 \\
\hline Agust I & 0,42 \\
\hline Agust II & 0,36 \\
\hline Sept I & 0,42 \\
\hline Sept II & 0,48 \\
\hline Okt I & 0,46 \\
\hline Okt II & 0,44 \\
\hline Nop I & 0,23 \\
\hline Nop II & 0,28 \\
\hline Des I & 1,30 \\
\hline Des II & 1,12 \\
\hline
\end{tabular}

Tabel 3. Perhitungan Kebutuhan Air (NFR)
4. Perhitungan Debit Rencana Saluran

Kebutuhan air maksimum ditetapkan 1,39 Itr/dtk/ha, untuk menghitung kapasitas rencana pembagian air bila 
$Q_{\text {maks }}=100 \%$

\section{Saluran Sekunder (SSR)}

A $\quad=729,09 \mathrm{Ha}$ (Luas areal)

C $=1$

$\mathrm{NFR}=1,39 \mathrm{ltr} / \mathrm{dtk} / \mathrm{ha}$

$Q s=c . N F R . A$

$=1 \times 1,39 \mathrm{ltr} / \mathrm{dtk} / \mathrm{Ha} \times 729,09 \mathrm{Ha}$

$=1012,59 \mathrm{Itr} / \mathrm{dtk}$

$$
\begin{aligned}
\text { Qrenc } & =\frac{Q s}{e} \\
& =\frac{1012,59}{0,9 \times 0,9 \times 0,8} \\
& =1.526,65 \mathrm{Itr} / \mathrm{dtk} \\
& =1,56265 \mathrm{~m}^{3} / \mathrm{dtk}
\end{aligned}
$$

5. Perhitungan Dimensi Saluran

Direncanakan dengan saluran berbentuk persegi.

\section{Saluran Sekunder SSR}

Data saluran

$$
\begin{aligned}
A & =729,09 \mathrm{Ha} \\
Q & =1,56265 \mathrm{~m}^{3} / \mathrm{dtk} \\
K & =75 \\
W & =0,25 \mathrm{~m} \\
b / h & =2,0 \\
b & =h \\
V_{\text {ijin }} & =0,37 \mathrm{~m} / \mathrm{dtk} \\
g & =9,81 \mathrm{~m} / \mathrm{dtk}^{2}
\end{aligned}
$$

Direncanakan dengan penampang persegi panjang

$$
\begin{aligned}
A & =\frac{Q}{V} \\
& =\frac{1,56265 \mathrm{~m}^{3} / d t k}{0,37 \mathrm{~m} / d t k} \\
& =4,223 \mathrm{~m}^{2} \\
A & =b \times h \\
& =h \times h \\
4,223 & =h^{2}
\end{aligned}
$$

$$
\begin{aligned}
& h=\sqrt{4,223} \\
& =2,06 \mathrm{~m} \\
& \text { b }=h \\
& =2,06 \mathrm{~m} \\
& P=b+(2 . h) \\
& =2,06+(2 \times 2,06) \\
& =6,17 \mathrm{~m} \\
& \text { R }=\frac{A}{P} \\
& =\frac{4,223 m^{2}}{6,17 m} \\
& =0,6850 \mathrm{~m} \\
& V \quad=K \cdot R^{2 / 3} \cdot I^{1 / 2} \\
& I^{1 / 2}=\frac{V}{K \cdot R^{2 / 3}} \\
& I=\left(\frac{V}{K \cdot R^{2 / 3}}\right)^{2} \\
& =\left(\frac{0,37}{75 \times 0,6850^{2 / 3}}\right)^{2} \\
& =0,0000404
\end{aligned}
$$

\section{Kontrol froude :}

$$
\begin{aligned}
\mathrm{B} & =2,06 \mathrm{~m} \\
\mathrm{~h} & =2,06 \mathrm{~m} \\
\mathrm{~A} & =\mathrm{b} \cdot \mathrm{h} \\
& =2,06 \times 2,06 \\
& =4,24 \mathrm{~m}^{2} \\
\mathrm{~V} & =\frac{Q}{A} \\
& =\frac{1,563}{4,24} \\
& =0,37 \mathrm{~m} / \mathrm{dtk}
\end{aligned}
$$




$$
\begin{aligned}
& \text { Fru } \quad=\frac{V}{\sqrt{g x h}} \\
& =\frac{0,37}{\sqrt{9,81 \times 2,06}} \\
& =0,082<0,5 \text { (Aliran Subkritis) }
\end{aligned}
$$

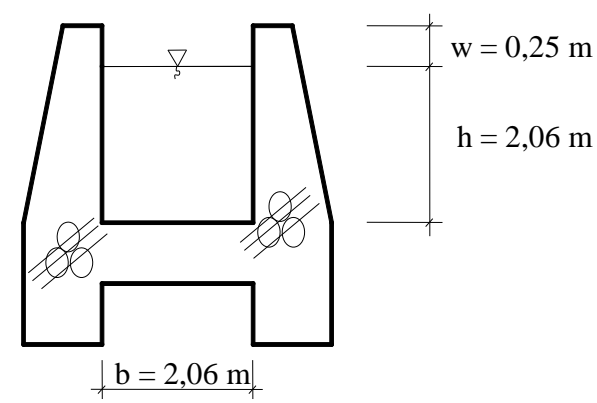

Gambar2.PenampangSaluranSekunder

\section{PENUTUP}

\section{Kesimpulan}

Berdasarkan pembahasan yang telah diuraikan maka dapat di ambil kesimpulan sebagai berikut :

1). Perhitungan Kebutuhan air irigasi menggunakan pola tata tanam "PadiPadi-Palawija" dengan mulai tanam pada bulan November I sampai dengan Bulan Januari II. Perhitungan dilakukan dengan enam alternatif tanam yakni periode tanam November I, November II, Desember I, Desember II, Januari I, Januari II.

Berdasarkan hasil perhitungan kebutuhan air maksimum tanaman dari alternatif periode tanam November I sampai dengan periode tanam Januari II maka didapatkan kebutuhan air di sawah (NFR) sebesar 1,39 ltr/dtk/ha.

2). Berdasarkan hasil perhitungan debit saluran dapat dimensi saluran dengan ukuran saluran sekunder sebagai berikut :

Lebar saluran $(b)=2,06 \mathrm{~m}$

Tinggi muka air $(\mathrm{h}) \quad=2,06 \mathrm{~m}$

Tingga jagaan $(\mathrm{w}) \quad=0,25 \mathrm{~m}$

\section{Saran}

Mengingat air merupakan kebutuhan yang sangat vital bagi suatu daerah irigasi maka diharapkan agar :

1). Untuk memperoleh hasil perhitungan yang optimal dalam analisa hidrologi suatu proyek irigasi, maka penulis menyarankan agar adanya data yang lengkap dan akurat sebagai penunjang perencanaan yang matang dan ketelitian dalam menganalisa data.

2). Untuk menjaga agar fungsi dari saluran tetap berfungsi dengan baik maka perlu adanya pemeliharaan yang rutin.

3). Untuk pemilihan pola tata tanam yang baik maka perlu diperhatikan faktorfaktor yang mempengaruhi pola tata tanam pada daerah tersebut karena karakteristik setiap daerah berbedabeda.

\section{DAFTAR PUSTAKA}

Direktorat Jenderal Pengairan, Departemen Pekerjaan Umum, 2010, Standar Perencanaan Irigasi Kriteria Perencanaan Jaringan Irigasi, KP-01.

Direktorat Jenderal Pengairan, Departemen Pekerjaan Umum, 2010, Standar Perencanaan Irigasi Kriteria Perencanaan Saluran, KP-03.

Direktorat Jenderal Pengairan, Departemen Pekerjaan Umum, 2010, Standar Perencanaan Irigasi Kriteria Perencanaan Bangunan, KP-04.

Hansen, Dkk, 1990, Arti Irigasi Secara Umum, Penerbit Erlangga, Jakarta.

C. D Soemarto, B.I.E. Dipl. H, 1999, Hidrologi Teknik, Penerbit Erlangga, Jakarta.

H.Erman Mawardi, Dipl. AIT,2002, Pengertian Irigasi, Alfabeta, Bandung.

Sri Harto Brotowiryatmo, Dip. H. 1993, Analisis Hidrologi, PT. Gramedia Pustaka Utama, Jakarta. 